\title{
LENGUAJE Y CONCIENCIA EN MICHEL FOUCAULT*
}

\author{
ÓSCAR MARTIARENA \\ FACULTAD DE FILOSOFIA Y LETRAS \\ UNIVERSIDAD NACIONAL AUTÓNOMA DE MÉxico
}

No deja de llamar la atención que Michel Foucault, cuyo trabajo filosófico estuvo siempre ligado íntimamente a la historia, quien con frecuencia hizo severas críticas a la razón y a sus estructuras y de alguna manera distanció su labor de la ciencia, se reclame a sí mismo como inscrito en la tradición filosófica abierta por Kant. Sin embargo, en un breve texto que el propio Foucault redactó con el seudónimo de Maurice Florence, destinado a aparecer en el Dictionnaire de philosophes ${ }^{1}$ y que buscaba dar una noticia de su obra, el filósofo francés escribe: "Si Foucault está inscrito en la tradición filosófica, es en la tradición de Kant, y podríamos llamar a su empresa Historia crítica del pensamiento."2

Ciertamente, el pensamiento de Kant aparece referido en varios de los textos de Foucault. Particularmente está presente en Las palabras y las cosas, donde Foucault ensaya una forma muy novedosa de hacer historia del pensamiento: la que el propio Foucault denominó arqueologia. Pero también Foucault se refiere a Kant en múltiples artículos, conferencias y cursos. Al respecto, destaca uno de sus últimos cursos en el Collège de France destinado a preguntarse, a la luz de Kant, ¿qué es la Ilustración? Asimismo, hay referencias a Kant en diversas entrevistas hechas a Foucault durante los últimos años de su vida, también relacionadas con la Ilustración y, en otra dirección, con La crítica de la razón práctica, en tanto que el último Foucault trabajó de cerca, como sabemos, problemas relacionados con la ética. Sin embargo, más que las referencias explícitas, es posible encontrar en la obra de Foucault, y desde muy pronto, rastros de una apasionada lectura de Kant, aunque quizá también habría que decir que son rastros que muestran una manera muy particular de asumir el pensamiento kantiano. Se trata,

* Texto presentado en el VII Congreso Nacional de Filosofía, en Aguascalientes/México, noviembre de 1995, en la mesa titulada "Lenguaje y conciencia".

1 D. Huisman, Dictionnaire de philosophes, P.U.F, Paris, 1984, pp. 942-944.

2 Ibid., p. 943. 
al parecer, de una manera singular de apropiarse del pensamiento de Kant. Una manera, si se quiere, muy "foucaulteana" de hacerlo, que tiene cierto parecido, por ejemplo, con la forma en la que Foucault, en otros momentos, se apropia del pensamiento de Nietzsche. En una entrevista en la que se le pregunta por su vinculación con el pensamiento nietzscheano, Foucault dice:

Yo, a las personas que me gustan las utilizo. La única prueba de reconocimiento que se puede manifestar ante un pensamiento como el de Nietzsche, es utilizarlo, deformarlo, hacerlo rechinar, gritar. ${ }^{3}$

Y, en buena medida, Foucault hizo lo propio con Kant: utilizarlo. En concreto, se trata de un uso de ciertos conceptos kantianos que trabajados peculiarmente, dan un resultado que quizá no era de esperarse si Foucault hubiese conducido en forma, digamos, "ortodoxa" los planteamientos kantianos. Al respecto, desearía tatar de pensar aquí la manera peculiar en que Foucault se vincula con el pensamiento de Kant en relación con la noción foucaulteana de a priori histórico.

La noción de a priori aparece muy pronto en los trabajos de Foucault. En un artículo publicado en 1957 que lleva el título de "La investigación científica y la psicología", ${ }^{4}$ Foucault se pegunta por el a priori histórico de la psicología, y lo hace en la dirección de un interrogarse por las condiciones de posibilidad que hacen de la psicología una ciencia o simplemente una práctica. Sin embargo, a pesar de utilizar el término, no hay una particular explicación del mismo.

En la Historia de la locura en la época clásica, presentada por Foucault en 1961 como tesis doctoral, nuevamente aparece el término a priori, aunque ahora en un uso que si bien está emparentado con el arriba mencionado, es más explícito. En la Historia de la locura..., Foucault busca mostrar que la unidad de los discursos alrededor de los locos se establece a patir de las diferentes formas en las que discursos específicos y prácticas concretas constituyen la locura en una época determinada. Esto es, sostiene que la locura se constituye en la medida de la emergencia de las descripciones médicas que la objetivan, de la existencia de medidas de exclusión que establecen las líneas de sombra entre los locos y los cuerdos, de la formación de discursos filosóficos que dan cuenta de lo que debe ser la razón y qué es la sinrazón, de la fundación de instituciones que la confinan, de la presencia

3 "Entretien sur la prison: le livre et sa méthode", en Foucault, M., Dits et écrits, Gallimard, Paris, 1994, t. III, p. 753.

4 "La recherche scientifique et la psycologie", en Foucault, M., Dits et écrits, t. I, pp. 137158. 
de obras literarias e imágenes pictóricas que la expresan y le asignan un lugar.

Como puede suponerse, en la Historia de la locura. . la posición de Foucault es la de un claro desplazamiento en relación con la psicopatología, a la que considera carente de cientificidad. Para Foucault la psicopatología es resultado de una yuxtaposición entre una conciencia social que decide si un individuo debe ser internado en un hospital psiquiátrico y una conciencia jurídica que se interroga si el individuo en cuestión es normal o no. En esta dirección, Foucault identifica la "medicina del espíritu" como una práctica; incluso construye la noción de homo natura bajo las condiciones que le imponen la conciencia social y la jurídica brevemente descritas. A patir de lo anterior y utilizando la noción de a priori, Foucault afirma:

La ciencia positiva de las enfermedades mentales y esos sentimientos humanitarios que han ascendido al loco al rango de ser humano sólo han sido posibles una vez sólidamente establecida esta síntesis, que forma, en cierto modo, el a priori concreto de toda nuestra psicopatología con pretensiones científicas. ${ }^{5}$

Ahora bien, como podemos ver, la noción de a priori que utiliza Foucault es distinta a la de Kant, fundamentalmente porque el a priori en el que a los ojos de Foucault se funda la psicopatología, no se localiza en el ámbito del sujeto, sino en el del discurso y la práctica misma de la psicopatología.

Utilizando un método semejante al que aplicó en la Historia de la locura..., Foucault emprendió la tarea de hacer una historia de la clínica moderna que dio como resultado el libro titulado El nacimiento de la clínica, publicado en 1963. Aquí la referencia a Kant y a la noción de a priori es mucho más explícita. En las primeras páginas del libro y en relación con el a priori de la clínica, Foucault afirma:

La medicina como ciencia clínica apareció en condiciones que definen, con su posibilidad histórica, el dominio de su experiencia y la estructura de su racionalidad. Éstas forman, su a priori concreto que es ahora posible sacar a luz, quizá porque está por nacer una nueva experiencia de la enfermedad, que ofrece, sobre la que rechaza en el tiempo, la posibilidad, de una percepción histórica y crítica. ${ }^{6}$

En esta dirección, Foucault considera que la tarea crítica propia de nuestro tiempo es distinta de la que Kant enfrentó. Al respecto, señala:

5 M. Foucault, Historia de la locura en la época clásica, FCE, México, 1986, vol. I, p. 208.

6 M. Foucault, El nacimiento de la clínica, Siglo XXI, México, 1975, p. 9. 
Para Kant, la posibilidad de una crítica y su necesidad estaban vinculadas, a través de determinados contenidos científicos, al hecho de que hay un conocimiento. En nuestros días están vinculadas - y el Nietzsche filólogo es testimonio de ello- al hecho de que hay un lenguaie y de que, en las palabras sinnúmero pronunciadas por los hombres - sean ellas razonables o insensatas, demostrativas o poéticas - ha tomado cuerpo un sentido que cae sobre nosotros, conduce nuestra ceguera, pero espera en la oscuridad nuestra toma de conciencia para salir a la luz y ponerse a hablar. Estamos consagrados históricamente a la historia, a la construcción paciente de discursos sobre discursos, a la tarea de oír lo que ya se ha dicho... ${ }^{7}$

Con estas premisas, Foucault inscribe su investigación sobre el surgimiento de la clínica en una perspectiva crítica, que le permitirá conocer las condiciones de posibilidad, esto es, el a priori, en el que la clínica se constituyó. Así, anota:

La búsqueda aquí emprendida implica por lo tanto el proyecto deliberado de ser crítica, en la medida en que se trata, fuera de toda intención prescriptiva, de determinar las condiciones de posibilidad de la experiencia médica, tal como la época moderna la ha conocido. ${ }^{8}$

En El nacimiento de la clínica, lo que Foucault busca es estudiar cómo un nuevo tipo de sujeto enfermo va a ser fundado por una nueva mirada del médico, y en esta medida mostrar que es en la trama de la formulación de la medicina emergente donde se asignan los lugares correspondientes a "médicos" y "enfermos". En esta dirección, Foucault busca mostrar que no son los "objetos" los que esperaban ser develados para su conocimiento; lo que la clínica más bien inaugura es un espacio de observación en el que los individuos enfermos son percibidos con base en una experiencia que no es sólo la de la objetividad científica, sino un dominio heterogéneo cuya unidad se encuentra conformada por medidas políticas (el combate de las epidemias y la necesidad gubernamental de organización social), medidas económicas (la reducción del gasto económico pagado por el Estado en la atención a los pobres), una nueva organización de la enseñanza de la medicina (el establecimiento de una educación reglamentada para limitar el abuso de quienes se hacen pasar por médicos), la formación de discursos en torno a las ventajas de la salud, la generalización de las autopsias, los discursos "filantrópicos". En suma, para Foucault, este entramado de discursos y prácticas diversos constituyó las condiciones de posibilidad, esto es, el a priori, de la experiencia clínica.

7 Ibid., p. 10.

8 Ibid., p. 15. 
Ahora bien, con los elementos enunciados, ya podemos tener una caracterización más precisa de la utilización foucaulteana de la noción de a priori. En El nacimiento de la clínica, Foucault piensa el a priori ciertamente como condiciones de posibilidad de la formación de un conocimiento, sin embargo estas condiciones de posibilidad, a diferencia de Kant, no se encuentran del lado del sujeto. Tal como lo hace Nietzsche en la Genealogía de la moral, Foucault privilegia al lenguaje como objeto de su análisis, aunque tal vez sería necesario decir que Foucault no entiende el lenguaje como sistema general de signos. Más bien piensa en el lenguaje efectivo, en el lenguaje que se realiza en discursos específicos. $Y$ es en el lenguaje en este sentido donde Foucault busca aprehender precisamente las condiciones de posibilidad de la emergencia de un conocimiento. Es decir, a diferencia de Kant que busca en el sujeto las condiciones de posibilidad del conocimiento, Foucault tiene la intuición de que es factible analizarlas en el ámbito de la constitución de los discursos. En este sentido, la tarea que Foucault realiza en El nacimiento de la clínica es similar a la de la Historia de la locura. .. , pero ahora precisa más su proceder, añadiendo que, dado que los discursos no permanecen en el tiempo, es decir, son históricos, lo que podrá advertirse es que las condiciones de posibilidad de los discursos son también históricas. Lo que produce, a la luz del pensamiento de Kant, una paradoja: que en las búsquedas foucaulteanas el a priori, como podemos ver es histórico.

Es conveniente recordar ahora que lo realizado en la Historia de la locura... y en El nacimiento de la clínica, Foucault lo llama arqueología. Fundamentalmente porque lo que ahí plantea no es sólo una historia de las ideas, sino una búsqueda de las condiciones de posibilidad, es decir, del a priori histórico, que permitió la formación de los discursos y de las ideas mismas.

Ahora bien, la intuición de que era factible encontrar las condiciones de posibilidad de los discursos y las ideas, llevó a Foucault a emprender una investigación más amplia y de mayores pretensiones cuyos resultados se condensan en Las palabras y las cosas, publicado en 1966. El subtítulo de Las palabras y las cosas es Una arqueología de las ciencias humanas. En esta búsqueda arqueológica, Foucault se interroga por las condiciones de posibilidad de las ciencias humanas; es decir, Foucault buscará conocer el a priori histórico que permitió la constitución de este saber y de su objeto: el hombre.

En las primeras páginas de Las palabras y las cosas, Foucault señala que en toda cultura existen códigos fundamentales que constituyen los órdenes empíricos a partir de los cuales es posible que los hombres puedan reconocerse y convivir (lenguaje, esquemas perceptivos, jerarquía de sus prácticas, técnicas, valores); asimismo, que a la par de estos códigos, las ciencias y las filosofías dan cuenta de la existencia de un orden en general caracte- 
rístico de la propia cultura, de las leyes que lo gobiernan y establecen las razones de la existencia de ese orden particular, y no de otro. Pero Foucault apunta también que, entre estas dos regiones, existe otra intermedia que, alejándose de los órdenes empíricos prescritos por sus códigos fundamentales y del conocimiento reflexivo, hace surgir la experiencia del orden como tal. Para Foucault, es en esta región donde una cultura se da cuenta de que sus codificaciones primarias no son las únicas posibles, ni tal vez las mejores; es aquí donde el orden emerge en su ser en bruto; es a partir de esta experiencia intermedia que las teorías generales del ordenamiento pueden incluso ser discutidas.

De esta experiencia "desnuda" del orden, Foucault pretende hacer la arqueología. Es decir, busca el a priori histórico que establece, en nuestra cultura, las condiciones de posibilidad de las ciencias humanas. En particular, Foucault dice de su trabajo:

es un estudio que se esfueza por reencontrar aquello a partir de lo cual han sido posibles conocimientos y teorías; según qué espacio de orden se ha constituido el saber; sobre el fondo de qué a priori histórico y en qué elemento de positividad han podido aparecer las ideas, constituirse las ciencias, reflexionarse las experiencias en las filosofías, formarse las racionalidades para anularse y desvanecerse quizá pronto. ${ }^{9}$

En Las palabras y las cosas, Foucault afirma que, en su trayecto, no hará una historia de las ideas, ni del progreso de los conocimientos hacia su objetividad, sino más bien una arqueología de las condiciones de posibilidad, léase a priori histórico, del saber. Este a priori histórico por investigar, Foucault lo llama en su tercera arqueología episteme. Foucault define episteme como el conjunto de relaciones que permiten, en una época determinada, la formación de prácticas discursivas que a su vez pueden constituir "figuras epistemológicas" como ciencias o sistemas formalizados. La tarea que Foucault se impone en esta "arqueolgía de las ciencias humanas" es entonces describir las reglas de formación, transformación y emergencia de los enunciados de tres diferentes segmentos epistemológicos localizados en la producción discursiva de Occidente a partir del Renacimiento: la semejanza renacentista, la Representación de los siglos xvI y xviI, y la Historia que arranca en el siglo xx.

En el desarrollo de su tercera arqueología, Foucault muestra que cada segmento epistemológico obedece a determinadas reglas que le son específicas y que, a su vez, son distintas las unas de las otras. Es decir, que las figuras epistemológicas propias de los siglos xvI y xvil como la Gramática

9 M. Foucault, Las palabras y las cosas, Siglo XXI, México, 1990, p. 7. 
General, la historia natural y el análisis de las riquezas, no son el antecedente histórico en tanto devenir del saber, de la lingüística, de la biología y de la economía política, sino que cada bloque es fruto de reglas de formación distintas, de campos epistemológicos diversos y, por lo tanto, de condiciones de posibilidad diferentes.

Una consecuencia inmediata y problemática se tiene ante los ojos. Las teorías contemporáneas creen encontrar sus antecedentes desde el Renacimiento. Foucault quiere mostrar, por medio de su arqueología, que el pensamiento occidental presenta dos grandes discontinuidades en lo que respecta a las condiciones de posibilidad del saber y que, por tanto, las búsquedas de antecedentes teóricos por parte de nuestra modernidad carecen de sentido o que sólo lo tienen en el nivel doxológico.

Específicamente para el campo de las ciencias humanas el resultado al que las lleva la arqueología foucaulteana es preguntarles por su objeto: el hombre. Foucault muestra que el hombre, en tanto objeto de conocimiento, data de fines del siglo xviI y, con ello, que las condiciones de posibilidad que permitieron la formación de las ciencias humanas, esto es, su a priori histórico, es muy reciente. Pero además, Foucault sugiere que dado que el hombre, como objeto de conocimiento, es producto de una episteme específica, bien puede pensarse que su figura epistemológica está destinada a desaparecer. Al final de Las palabras y las cosas podemos leer:

Si esas disposiciones desaparecieran tal como aparecieron, si, por cualquier acontecimiento que cuando mucho podemos presentir, pero cuya forma no conocemos por ahora, oscilaran, como lo hizo, a fines del siglo xvin el suelo del pensamiento clásico, entonces podría apostarse que el hombre se borraria, como en los límites del mar un rostro de arena. ${ }^{10}$

Como podemos ver, la peculiar forma de utilizar el pensamiento kantiano, particularmente en Las palabras y las cosas, condujo a Foucault a obtener conclusiones severas que en su momento hicieron de su texto un libro polémico, aunque tal vez lo siga siendo. Pero más allá de ellas, vale la pena volver aún a la noción foucaulteana de a priori histórico.

Con las premisas anteriores y a partir de algunos señalamientos de Gilles Déleuze en su Foucault ${ }^{11}$, es posible aproximarnos a la noción de a priori histórico. Como hemos visto, en Foucault, el a priori a) se encuentra del lado del lenguaje o mejor, de discursos específicos; b) no se encuentra del lado del sujeto; más aún, el sujeto se constituye en sujeto, precisamente en tanto ocupa un lugar de enunciación en los ámbitos

10 Ibid., p. 375.

11 G. Deleuze, Foucault, Les édition de Minuit, Paris, 1986, p. 67. 
discursivos, lo que significa que el a priori también lo es para la constitución de los sujetos del discurso; c) para su análisis supone un corpus discursivo específico; d) es histórico, en tanto los discursos que permiten analizarlo también lo son. $\mathrm{Y}$ añadiríamos además otra característica que se desprende de los discursos estudiados: en todo momento, los analizados por Foucault son aquellos discursos en los que el sujeto se convierte en objeto de conocimiento, es decir, en las llamadas ciencias humanas.

En La arqueología del saber, libro en el que se detiene a pensar sus primeras investigaciones, Foucault es consciente de lo paradójico que puede parecer que un a priori sea histórico. Al respecto señala:

Yuxtapuestos esos dos términos hacen un efecto un tanto detonante [...] La razón de utilizar este término un tanto bárbaro, es que este a priori deber dar cuenta de los enunciados en su dispersión, en todas las grietas abiertas por su no coherencia [...]; en suma, ha de dar cuenta del hecho de que el discuso no tiene únicamente un sentido o una verdad, sino una historia, y una historia específica que no lo lleva a depender de las leyes de un devenir ajeno. ${ }^{12}$

Es decir, al buscar el a priori de los discursos, lo que Foucault quiso hacer fue pensar los discursos como tales, más allá de supuestas correlaciones previas que pretendieran establecerse por fuera de los discursos mismos. En esta direccion, el a priori de los discursos es histórico en tanto analiza el conjunto de reglas que son propias de las prácticas discursivas, en tanto éstas emergen, permanecen y desaparecen históricamente, independientemente de los sujetos que se juegan, e incluso se constituyen, precisamente en el ámbito de los discursos. De hecho, Foucault se resiste a suponer la trascendencia del discurso y la existencia de una subjetividad que supuestamente lo gobernara. ${ }^{13}$ Mas aún, Foucault sostiene, y cree poder demostrarlo mediante su arqueología, que las distintas formas de apropiación de los discursos varían con cada cultura y se modifican siguiendo sus propias veredas.

Ahora bien, Foucault señala que todo este trabajo tenía un fin muy específico. En las últimas páginas de La arqueología del saber señala:

me he obstinado en avanzar. Y no porque esté seguro de la victoria ni confíe en mis armas, sino porque me ha parecido que, por un instante, ahí estaba lo esencial: liberar la historia del pensamiento de la sujeción trascendental [...]; se trataba de analizar esa historia en una discontinuidad que ninguna

12 M. Foucault, La arqueología del saber, Siglo XXI, México, pp. 215-216.

13 "He desconocido la trascendencia del discurso; me he negado al describirlo a referirlo a una subjetividad. ..", Ibid., p. 335. 
teleología reduciría de antemano; localizarla en una dispersión que ningún horizonte previo podría cerrar; dejarla desplegarse en un anonimato al que ninguna constitución trascendental impondría la forma de sujeto; abrirla a una temporalidad que no prometiese la vuelta de ninguna aurora. Se trataba de despojarla de todo narcisismo trascendental. . ${ }^{14}$

Pero despojar a la historia, aunque también a las ciencias humanas, de su "narcisismo trascendental" equivale en Foucault a mostrar que el sujeto no es la conciencia totalizadora de todo pasado y todo devenir; pero además, equivale a negar que la conciencia sea la portadora de todo saber y práctica posibles. Asimismo, implica poner en tela de juicio las continuidades y los fines e interrogar sobre la pertinencia de las totalizaciones históricas. Finalmente, conlleva una severa crítica a todo aquel pensamiento que sostiene que el hombre es la conciencia trascendental del saber. En Las palabras y las cosas, al analizar el a priori histórico que emerge a fines del siglo xvin, Foucault muestra cómo surge la paradójica figura del hombre, epistemológicamente hablando, como pliegue empírico-trascendental; es decir, como objeto por conocer y como sujeto que conoce. Situación que impide al propio hombre ser la conciencia del saber, ya que a cada hallazgo corresponde un nuevo momento de desconocimiento. Asimismo, permite a Foucault reconocer las reglas y el funcionamiento de las ciencias humanas en ese último capítulo de Las palabras y las cosas del que un filósofo como Habermas dice:

Partiendo de este dilema de la autoobjetivación y también del autorredoblamiento empirico-trascendental del sujeto cognoscente, Foucault ha sido el último en desarrollar, en el impresionante capitulo final de Las palabras y las cosas, una crítica de la subjetividad a la que apenas si es posible hacer frente de otro modo que con un cambio de paradigma. ${ }^{15}$

En esta dirección, el camino de Foucault fue, en lugar de pensar que la conciencia se encuentra en un sujeto que podría pensarse como trascendental, analizar más bien las formas en las que el lenguaje se realiza en discursos específicos y la manera en la que el sujeto se sitúa e incluso se construye históricamente, en el entramado de los mismos. En el texto que escribe sobre Maurice Blanchot, aparece también la cuestión del sujeto y del lenguaje. Ciertamente, la conciencia del sujeto no es lo que ahí importa. Citaré algunas frases cortas pero que ilustran la manera en que Foucault entiende ahí la relación entre la conciencia del sujeto y el lenguaje: "El ser del

14 Ibid., p. 340.

15 J. Habermas, Pensamiento postmetafísico, Taurus Humanidades, México, 1990, p. 272. 
lenguaje no aparece por sí mismo más que en la desaparición del sujeto"16; "todo sujeto no representa más que un pliegue gramatical"17; finalmente, "ahora se sabe que el ser del lenguaje es la visible desaparición de aquel que habla"18.

Es precisamente en este sentido que Foucault afirma que la conciencia del sujeto no puede aparecer como titular del lenguaje, sino que la propia conciencia del sujeto se constituye en el ámbito del lenguaje mismo. En esta dirección, es claro que la conciencia del sujeto que Foucault estudia a partir de un análisis de los a priori presentes en los discursos de las ciencias humanas queda situada, definida, fija, invariable, neutralizada por las reglas de los discursos mismos. Por tanto, Foucault puede afirmar que el analizado en su arqueología es un sujeto siempre dependiente del lenguaje, es decir, de los discursos mismos. Pero si esto es efectivamente así, entonces bien se puede preguntar: ¿acaso no hay otra dimensión para el sujeto más que la de sujetar su conciencia a los ámbitos normativos de los discursos que lo objetivan de acuerdo con a priori históricos específi$\cos$ ?

Foucault considera que sin duda existen esas otras dimensiones para la subjetividad. Ciertamente, el sujeto puede ser" creador de ámbitos de subjetividad no normada por los discursos que lo objetivan. Foucault consideró que una forma de encaminarse hacia esos ámbitos en los que el sujeto puede ser más que un simple pliegue en el velo del lenguaje, era comenzar con la realización de una historia crítica del pensamiento. Una historia que, partiendo de una crítica de la sujeción trascendental de los discursos que objetivan a los seres humanos, abriera quizá la posibilidad de la constitución de un nuevo a priori histórico en el que nos sea lícito pensar de otra manera. Al realizar esta labor, Foucault quiso situarse, como mencionamos al referirnos a ese texto en el que fija su inserción en la filosofía, en el horizonte filosófico inaugurado por Kant, aunque, como pudimos advertirlo, en una forma muy peculiar. Tal vez haciendo rechinar las palabras, los conceptos kantianos, como en el caso de la noción de a priori. Pero podríamos agregar que esta forma tan peculiar de trabajar a Kant fue en Foucault verdaderamente fecunda, fundamentalmente si pensamos que este uso singular lo condujo a cuestionar la normatividad de los discursos que nos objetivan, en particular los discursos de las ciencias humanas. Sobre todo si pensamos también que de lo que se trata es de mostrar que lo que importa, más que el sujeto tras-

16 M. Foucault, El pensamiento de afuera, Pretextos, Valencia, 1988, p. 16.

17 Ibid., p. 74.

18 Ibid. 
cendental, somos los sujetos de todos los días. ${ }^{19} \mathrm{Y}$ en este sentido, me parece que en el uso poco ortodoxo de la noción kantiana de a priori, aunque sin duda no sólo en ello, a Foucault le tendríamos que dar la razón.

19 ¿Por qué afirmar esto? Una constante en las diversas investigaciones de Foucault fue la preocupación por la forma en que se constituyen históricamente las ciencias humanas y las formas en que nos objetivan, es decir, convierten los seres humanos en objetos de conocimiento. En este sentido, pensar el a priori foucaulteano, remitido fundamentalmente al lenguaje y a condiciones históricas específicas, lleva a pensar que el propio sujeto de conocimiento se constituye históricamente. Dicho de otra manera: que el sujeto que conoce (sujeto trascendental) es histórico y no dado de una vez y para siempre. Aunado a lo anterior, en libros como Historia de la locura en la época clásica, en El nacimiento de la clínica y más tarde en Vigilar y castigar, Foucault busca mostrar cómo el propio sujeto de conocimiento de las ciencias humanas objetiva a partir de las condiciones históricas de posibilidad que le da el ejercicio de poder sobre los individuos: condiciones de encierro. En esta dirección, las investigaciones de Foucault conllevan, como puede verse, una severa crítica a la constitución del sujeto de conocimiento de las ciencias humanas (crítica que, como señalamos arriba, de alguna manera comparte Habermas en relación con la autoobjetivación). Pero además, los trabajos de Foucault implican también una llamada de atención sobre la forma en que las ciencias humanas objetivan a los sujetos de todos los días, es decir, a los hombres y mujeres comunes y corrientes, que son convertidos en objetos de conocimiento por un sujeto que construye su saber a partir del ejercicio del poder. 